westward to Sarra and the Tibesti foothills. It is centred about lat. $21^{\circ} 16^{\prime} \mathrm{N}$., long. $24^{\circ} 14^{\prime} \mathrm{E}$, with a radius of about six miles, and most of its denuded stumps were visited by Lieut. D. R. Paterson and myself. There seem to be no explosion craters in this group.

Each 'field' is associated with very slight folds of the Nubian sandstone, and the complex of ancient rocks upon which it lies is exposed in the immediate vicinity by the denudation of the slight surviving thickness of sandstone. The period of volcanicity is obviously far younger than the Nubian series, and the fresh appearance of the explosion craters suggests a fairly recent date of formation.

The discovery of a few stone implements of Middle Palæolithic type in and near some of the craters necessitates a readjustment of ideas, which is confirmed by comparison with the great crater of Malha, in the Meidob Hills about 150 miles north - north - east of Fasher. Malha seems to have exploded but yesterday: the basaltic lavas which surround it and have flowed into one corner of it are fresher than many on the flanks of Vesuvius, yet the traditions among the people who depend on the springs within it seem to recall only variations of level of the lake in its centre. These explosion craters seem to be far older than they at first appear.

The presence of light trachytic rocks within a radius of about 50 miles from Gebel 'Uweinat is of interest in contrast to the wide distribution of basalt and dolerite over Egypt and the Sudan, ranging from an Oligocene age in Egypt to at least a semi-recent age at Malha. About 'Uweinat the dolerites seems to be of far greater age than the features described above, but there was a later effusion of basaltic magma at Malha-the presence of basaltic lava and of 'volcanoes' in the Bayuda desert between Berber and Merowe (Dongola) will be recalled-probably long after the trachytes of 'Uweinat were cold.

\title{
The Old Morphology and the New*
}

By Dr. H. Hamshaw Thomas

"T HE full problem of morphology is . . . to explain how in the past plants came to be such as we now see them" (Bower). The problem is often regarded as insoluble, but a survey of the development of morphological concepts suggests that some of our difficulties may be due to the tacit acceptance of theories handed down by successive generations of teachers. In dealing with the flowering plants, almost all recent writers accept the classical concepts originated by Goethe and Lindley in pre-evolutionary days. During the last thirty years, however, a large body of facts has been accumulated about the simpler and older plants, and a new system of ideas has been founded, which is in harmony with our knowledge of the form of the earliest known Devonian land plants. We have now to face the question of the relation between the fundamental concepts of the old morphology and those of the new.

At the outset of any discussion of form, it is necessary to keep in mind the principles underlying our comparisons. In the past, before the coming of evolution, comparisons of plants were mainly subjective, but to-day we aim at an objective approach. Plants are objectively comparable because we consider them to be derived from common ancestors; if we reject the subjective approach, we must introduce phylogenetic considerations.

We owe the term 'morphology' and the foundation of the classical concepts to the poet philosopher, Goethe, who published in 1790 a treatise "On the Metamorphosis of Plants", which has been called "the foundation of all that has since been done in vegetable morphology". The most important conclusion in this essay is that "whether a

* From a paper raad to the Linnean Society of London on November 10,1932 . plant produces leaf-buds, flowers, or fruits it is still the same organ which is carrying Nature's laws into effect, though performing different offices and disguised under different forms". This one organ is called the leaf, but Goethe appeared to feel that it should be given some more generalised designation.

The spread of this doctrine in England was largely due to Lindley, who repeated Goethe's views and arguments, but he made an important modification in the theory which has received insufficient attention. Goethe wisely wrote near the close of his essay, "The thing now to be aimed at is to keep habitually in view the two contrary directions in which variations are developed. For we may say with equal truth that a stamen is a diminished petal or that a petal is an expanded stamen."

Lindley, however, concludes that "the leaf, as the first formed, the most perfect of all [the appendages] and that which is most constantly present, is properly considered the type from which all the others are derivations". 'This unsupported assumption was widely accepted, and Darwin in "The Origin of Species" spoke of the view that the parts of the flower consist of metamorphosed leaves as familiar to almost everyone. As the result of Darwin's work, the old concepts of the subjective and idealistic philosophers have been taken over and given an objective significance by biologists.

The doctrine of metamorphosis led to the idea that the parts of plants could be divided into three distinct eategories, stems, roots and leaves. This has met with less universal approval. It may be tenable when we are dealing only with the mostly highly evolved forms, but when an attempt is made to extend it downwards grave difficulties are encountered. It has resulted in an unnatural 
separation of the Thallophyta and Bryophyta from the higher forms.

The major concepts of the classical views have in the course of time come to be considered as so axiomatic that few writers have troubled about the evidence on which they were based, or have followed up their implications. But modern work has cast doubt on most of the arguments used in founding the system. Grégoire has found that the primordia of the stamens and carpels at their first appearance can be distinguished from those of foliage leaves, and so is led to the view that the stamens and carpels are organs sui generis. The validity of arguments based on abnormal flowers was challenged some years ago by the late Prof. K. von Goebel, and more recently by Mrs. Arber on the principle of irreversibility in evolution. Thus the only uncontested evidence is that derived from comparisons during the progressive growth of the plant, which, as Goethe pointed out, may be read in two opposite ways.

It might be reasonably expected that the great outburst of morphological research which followed the rise of the doctrine of evolution would provide evidence in support of the fundamental concepts. But no fresh evidence has been obtained. The continental morphologists of the classical school reject all evidence derived from the study of comparative anatomy and vascular structure as worthless, and they likewise seem to reject considerations of ontogeny, cytology and evidence derived from fossil plants. It may be that anatomical and developmental studies are held to have no bearing on morphology because they are known to conflict with the classical concepts. Most English morphologists regard anatomical and palæobotanical work as valuable, but in attempting to apply new knowledge to old concepts find that more problems are raised than solved.

The general ideas of the new morphology which may be said to have originated twenty-four years ago with the work of Lignier, Tansley and Bower, are based on considerations of phylogeny. The forms of plants and plant organs can only be explained by reference to their origin, and even though we cannot trace back the development of a group of organisms, we may in various ways obtain glimpses of the types of change which have gone on in the past. Fragments of the evolutionary history of one group may enable us to guess what has probably gone on in another group. The classes pteridophytes, gymnosperms and angiosperms may well represent stages in evolution rather than independent groups of organisms, and there is much evidence pointing to parallel evolution in the various groups. When endeavouring to draw the broad generalisations on which a system of morphology is based, it is unnecessary to trace the complete phylogenetic history of all the groups of plants, unless we consider that the different groups have been derived from independent algal ancestors, and that all traces of the previous history of many of them have been obliterated.
Even the present incomplete state of our knowledge enables us to determine the general trend of evolution throughout the ages with some degree of probability, and it may well be that the geological record of plant life is more complete than has previously been supposed. Any general system of morphological ideas should be applicable to all plants, but only one group has yet been fully studied from the new point of view. Prof. Bower's work on the ferns provides us with evidence as to the probable evolution of this group drawn from a number of different aspects. Zimmermann, in a publication of a different character, has shown how well the new views can be applied to the gymnosperms.

From a study of the Pteridophyta and the earlier fossil plants we are led to suppose that the very early land-plants were simple structures of the Rhynia or Psilophyton type, in which there is little differentiation beyond that of the sporangia. Afterwards roots became specialised from underground branches, and in some groups small simple leaves appeared. The large leaves characteristic of most of the higher plants seem to have evolved from branch systems and long retained traces of this origin. The primitive terminal sporangia either retained their original position or became involved in frond formation and attained a marginal or superficial position; they often formed tassel-like groups and frequently became more or less fused.

These generalisations are quite inconsistent with the classical ideas of morphological development, and call for a modification of our ideas of homologous structures. They suggest that the foliage leaves and reproductive organs of the flowering plants can only be regarded as homologous structures because they are both derived from branch systems. Stamens and carpels have never been typical leafy structures with an expanded lamina, and it is probably misleading to call them sporophylls.

These newer concepts help us to understand the gymnospermous reproductive organs. It is no longer necessary to assume that terminal ovules in Ginkgo and Ephedra were originally produced on lateral leafy organs which have disappeared without leaving the slightest trace of their former presence. There is a great gap between the Psilophytales and the flowering plants, but it is to some extent bridged by the upper Palæozoic pteridosperms. The derivation of the Caltha type of carpel from a Caytonia-like structure has already been suggested, and we can now link the Caytoniales more closely to the pteridosperms owing to the discovery in the Triassic rocks of South Africa of a new group of seed-bearing structures.

When we come to examine all the known pollenbearing structures of the seed plants with large leaves, it seems as though we can distinguish a gradual progression along two or three distinct lines, commencing with terminal groups of separate sporangia produced in groups, and leading to Mesozoic structures which may either be like branched stamens, structures bearing bean-shaped 
synangia, groups of sporangia borne on the surface of a leaf-like structure, or organs resembling the male flowers of the poplar. Nothing is known of a fertile leaf like that envisaged in the classical morphology. The study of these forms, however, suggests that angiospermous flowers may have originated in more than one way.

When we examine the forms of expanded leaves throughout the past, it is impossible to avoid the conclusion that 'compound' leaves are of a more primitive type than 'simple' leaves. In certain cases, however (for example, the Date palm), a new type of compound leaf has probably arisen from a simple form.

In other branches of science the interpretation of observed facts is facilitated by making successive assumptions and by comparing the theoretical results of each with the observations already made. This procedure has not been followed in plant morphology. The old system provided one set of assumptions only, founded more than a century ago on a very imperfect knowledge of the plant world, and for many years endeavours have been made to harmonise our ever-increasing observations with these postulates, distorting or discarding all those facts which seemed inconsistent. While it is quite probable that the assumptions of the new morphology may prove to need drastic emendation, they may nevertheless serve a useful purpose in the study of plant evolution.

\section{Obituary}

\section{Mr. H. A. RoBerts}

$\mathrm{M}^{\mathrm{R}}$ R. H. A. ROBERTS, secretary for thirty years of the Appointments Board of the University of Cambridge, died at Cambridge on December 18 at the age of sixty-eight years. After ten years as senior mathematical master at Bath College he returned to Cambridge as a coach in mathematics in 1898. But his life's real work began when he was appointed in 1902 to be secretary of the University Appointments Board. He waskeen to develop a new line of openings for university graduates in business and administrative posts, in addition to the more obviously natural academic, professional and technical positions which most men then sought after graduation. By great care in the selection of the men whom he recommended to the firms which applied to the Board, he not only succeeded in overcoming a prejudice against university men in business but he also created a new demand for such men on the part of large industrial undertakings.

Thirty years of devoted service on Mr. Roberts's part brought their own reward in intimate and friendly relations with the heads of industry, with their younger successors who had gone into business under his auspices, and with generations of college tutors, with whom he always worked in the closest touch. Gonville and Caius College elected Mr. Roberts as a Fellow in 1927, his advice was sought in Government circles and in the formation of appointments boards at other universities and for the women's colleges at Cambridge. He retired on account of ill-health only last autumn. It is sad that he should have lived so short a time to enjoy his hard-won leisure, but it is something that he was able to attend, less than a fortnight before his death, a complimentary dinner at which a presentation was made to him on his retirement by a number of those whom he had served so well.

\section{Mr. A. R. WRIGHT}

Mr. A. R. Wright, who died on December 24 at the age of seventy years, played an important part in organising the work of the examining staff of the Patent Office to its present high level of efficiency and was also a recognised authority on folk-lore.

Wright entered the Patent Office in 1885 and from that date until his retirement forty-two years later worked unremittingly to place the classification of patent specifications for search purposes on a sure foundation. He was the editor of the well-known official series of illustrated class abridgment volumes which were published at the rate of more than fifty volumes a year to cover, by the year 1905, all patent specifications issued up to that time from 1855. The classification scheme on which this mass of material was indexed and through which alone the official search for novelty introduced by the Patents Act of 1902 was made possible, was largely Wright's work, and its amplification in subsequent years to meet the evergrowing amount of search material in the examiners' files and the development of industries and industrial processes was carried out under his personal supervision with a thoroughness and care for detail which were characteristic of the man.

The Patent Office classification as it stands to-day, exceptional in many respects, deserves a high place among the several developed classifications of applied science, and is a worthy memorial to Wright's energy and capacity. He was appointed assistant-comptroller of the Patent Office in 1922, while still retaining the classification as his main charge, and retired from the service in 1927.

As a folklorist, Wright was known not so much for his literary output, which was not large, as for his encyclopædic knowledge of folk beliefs and customs, obtained by extensive reading and an unusually retentive memory, which was ever at the disposal of anyone seeking information, and for the valuable services he rendered through the Folk-Lore Society, of which he became a member in 1890 . He was a prominent and active member of the Council of the Society from 1898 until his death, and president for the two years 1927 and 1928, while he was an invaluable editor of the Society's journal Folk-Lore from 1912 until 1931. 